\title{
The use of carbon nanomaterials in membrane distillation membranes: a review
}

\author{
Sebastian Leaper ${ }^{1}$, Ahmed Abdel-Karim ${ }^{1,2}$, Patricia Gorgojo (凶) ${ }^{1}$ \\ 1 Department of Chemical Engineering and Analytical Science, School of Engineering, The University of Manchester, Manchester, M13 9PL, UK \\ 2 Water Pollution Research Department, National Research Centre, Giza 12622, Egypt
}

(C) The Author(s) 2021. This article is published with open access at link.springer.com and journal.hep.com.cn

\begin{abstract}
Membrane distillation (MD) is a thermal-based separation technique with the potential to treat a wide range of water types for various applications and industries. Certain challenges remain however, which prevent it from becoming commercially widespread including moderate permeate flux, decline in separation performance over time due to pore wetting and high thermal energy requirements. Nevertheless, its attractive characteristics such as high rejection (ca. 100\%) of nonvolatile species, its ability to treat highly saline solutions under low operating pressures (typically atmospheric) as well as its ability to operate at low temperatures, enabling waste-heat integration, continue to drive research interests globally. Of particular interest is the class of carbon-based nanomaterials which includes graphene and carbon nanotubes, whose wide range of properties have been exploited in an attempt to overcome the technical challenges that MD faces. These low dimensional materials exhibit properties such as high specific surface area, high strength, tuneable hydrophobicity, enhanced vapour transport, high thermal and electrical conductivity and others. Their use in MD has resulted in improved membrane performance characteristics like increased permeability and reduced fouling propensity. They have also enabled novel membrane capabilities such as in-situ fouling detection and localised heat generation. In this review we provide a brief introduction to MD and describe key membrane characteristics and fabrication methods. We then give an account of the various uses of carbon nanomaterials for MD applications, focussing on polymeric membrane systems. Future research directions based on the findings are also suggested.
\end{abstract}

Keywords carbon nanomaterials, graphene, membrane distillation, desalination, carbon nanotubes

Received April 1, 2020; accepted July 20, 2020

E-mail: p.gorgojo@manchester.ac.uk

\section{Introduction}

1.1 Membrane distillation (MD)

MD is a non-isothermal phase separation process in which a hydrophobic porous membrane prevents the passage of the liquid phase (typically water), retaining all non-volatile species dissolved within it, but allows the passage of vapours [1]. The temperature difference across the membrane sets up a vapour pressure difference along which the vapours will travel. This difference in vapour pressure is the fundamental driving force behind this process, unlike conventional filtration processes which are based on hydraulic pressure or concentration gradients [2]. In this way, species can also be separated according to their volatility by adjusting the feed temperature or permeateside absolute pressure (or both), although the wettability of such volatile components towards the membrane is a key consideration [3].

Recently, much progress has been made in the development of high-performance membranes for MD. A recent review of the use of nanomaterials in MD membranes can be found elsewhere [4]. Here, after providing a brief overview of the principles of MD and the key requirements for MD membranes, we focus specifically on carbon-based nanomaterials and the various ways in which their multifunctional properties can improve MD performance.

\subsubsection{Background}

In MD, heat and mass transfer are coupled and so the temperature difference across the membrane must be maintained by a continuous supply of heat [5]. Thermal conduction through the membrane can also reduce the temperature difference and thereby reduce the vapour pressure difference, lowering the permeate flux. Suitable membranes therefore need to have low through-plane 
thermal conductivity.

MD can operate at low temperatures with low grade heat sources such as solar thermal, geothermal, waste heat and even thermal gradients in the sea where the feed and permeate temperatures may be as low as $30^{\circ} \mathrm{C}$ and $10{ }^{\circ} \mathrm{C}$, respectively [6]. Many reports have suggested that when cheap sources of thermal energy are utilised, MD can be cost competitive with or even cheaper than reverse osmosis (RO) for sea water desalination, particularly on a small scale [6-8]. Although a lack of robust data on industrial MD implementation has resulted in large variances (nearly 4 orders of magnitude) in the values reported for produced water cost [9].

There are several other advantages to MD compared to conventional processes which make it attractive, including: simple operation with reduced need for pre-treatment, low electrical energy requirements, suitability for treating a wide range of wastewaters achieving $100 \%$, and reduced fouling propensity due to low operating pressure. In particular, its ability to treat highly saline water has made it attractive as a brine treatment process to be coupled with RO systems [10-13]. MD can be used in this way not only to reduce the rejected brine volume but also to controllably precipitate valuable crystals that can be sold. This hybrid membrane-crystallisation process was first proposed by Enrico Drioli's group in the mid-1980s [14,15] and has now been shown to recover specific crystal polymorphs [16] and a variety of other valuable feed water components such as lithium [17], phosphorus [18] and ammonia [19].

Despite mainly being studied for the purification of sea water and brines, MD is increasingly being applied to treat different water types. These include wastewaters from industries such as mining [20], textile dyeing [21,22], pharmaceutical [23], agriculture [24,25], space [26] as well as municipal sources [27]. Also, because it can operate at low temperatures, it has been applied to the beverage industry to concentrate fruit juices which can be spoiled by higher-temperature distillation processes [28].

There are four main MD configurations, classified according to the means by which the permeating vapour is collected. The simplest and most commonly studied configuration is direct contact MD (DCMD). In this case, the heated feed water and the cooler permeate stream are both in direct contact with the membrane and the vapour passing through the membrane condenses directly into the permeate stream. In the air-gap configuration MD (AGMD), the water vapour is condensed inside the membrane module onto a cooled condensing surface such as metal plate or foil. The fact that the condensation of the vapour occurs locally means that it is possible to recover much of the latent heat which, when arranged in a stacked or spiral wound configuration, can dramatically increase the thermal efficiency of the process, as reported by Andrés-Mañas et al. with a vacuum-enhanced AGMD pilot scale system [29]. This vacuum-enhanced air-gap configuration differs from the conventional vacuum $\mathrm{MD}$ (VMD) in that the water vapour in VMD is removed by a higher vacuum pressure and condensed externally. A less common configuration uses a flow of inert gas or air over the surface of the membrane on the permeate side. Socalled sweeping gas MD (SGMD) boasts lower mass transfer resistance than AGMD and suffers less conductive heat loss than DCMD [30]. However, the added complexity of having a gas continually pumped across the membrane surface has made it less attractive. More details on MD configurations can be found in the literature $[31,32]$.

\subsubsection{Membrane properties}

While there are various ways to fabricate MD membranes, in each case there are certain characteristics that are necessary for achieving good performance. The most significant ones are: 1) Thermal and chemical stability. This is an essential property for MD membranes not only because of the potentially high operating temperatures and harsh chemical feed water environments but also because of cleaning processes which often require moderately acidic and/or alkaline washing agents. Cleaning is necessary in all membrane processes to recover membrane performance lost due to fouling and extend the membrane lifetime. 2) Liquid entry pressure (LEP). This is the pressure required for water to wet the membrane and is a measure of its hydrophobicity. This is a parameter that can change over time due to membrane degradation or fouling and its reduction can lead to unwanted pore wetting which results in lower rejection. The addition of certain species such as oils or surfactants to the feed water can dramatically change the wetting propensity of a given membrane. The development of omniphobic membranes are an attempt to provide high LEP values for various feed waters, including those with low surface tension $[33,34]$. 3) Porosity. This is defined as the volume occupied by the pores divided by the total volume of the membrane. High porosity generally results in lower mass transfer resistance and so this increases the flux, although beyond a certain point the mechanical stability of the membrane will be compromised. Typical porosities for MD membranes are between $60 \%$ and $90 \%$. In this definition, the pores are assumed to be 'through-pores' meaning that there is an open channel allowing the permeating species to travel through the pore and thereby contribute to permeation. Certain 'porous' structures may have high free volume but may consist of closed cells. Such a structure may be useful for applications such as thermal insulation but clearly would be ineffective for membrane separation.

In addition to these three, other important parameters to consider are membrane thickness, mean pore size, maximum pore size (which is related to the LEP), pore size distribution, pore tortuosity and the thermal 
conductivity of the membrane [35]. Arguably the most significant membrane property is the LEP as it underpins the fundamental operating process of $\mathrm{MD}$, namely the prevention of liquid permeation while enabling efficient vapour permeation. The LEP can be calculated using Eq. (1):

$$
L E P=\frac{-B \gamma_{\mathrm{L}} \cos \theta}{r_{\max }},
$$

where $B$ is a geometric pore coefficient which is equal to 1 for cylindrical pores, $\gamma_{\mathrm{L}}$ is the liquid surface tension, $\theta$ is the contact angle, and $r_{\max }$ is the maximum pore size [36]. An ideal membrane would therefore have a high feed solution contact angle and a narrow pore-size distribution, free from large pores which could act as defects. Furthermore, significant reductions in flux can be incurred if the temperature difference between the bulk feed and the permeate is not maintained. This phenomenon is known as temperature polarisation and is a crucial consideration when designing membranes, particularly in DCMD. The temperature polarisation coefficient (TPC) is the ratio of the temperature differences at the membrane/bulk interface and is described by Eq. (2):

$$
T P C=\frac{T_{\mathrm{fm}}-T_{\mathrm{pm}}}{T_{\mathrm{fb}}-T_{\mathrm{pb}}}
$$

where $T_{\mathrm{fb}}$ and $T_{\mathrm{pb}}$ are the bulk temperatures of the feed and permeate, respectively, and $T_{\mathrm{fm}}$ and $T_{\mathrm{pm}}$ are the temperatures in the membrane surface on the feed and on the permeate sides, respectively [1]. Figure 1 depicts the temperature profile across the membrane in MD and the positions of the relevant temperature values for calculation of the TPC.

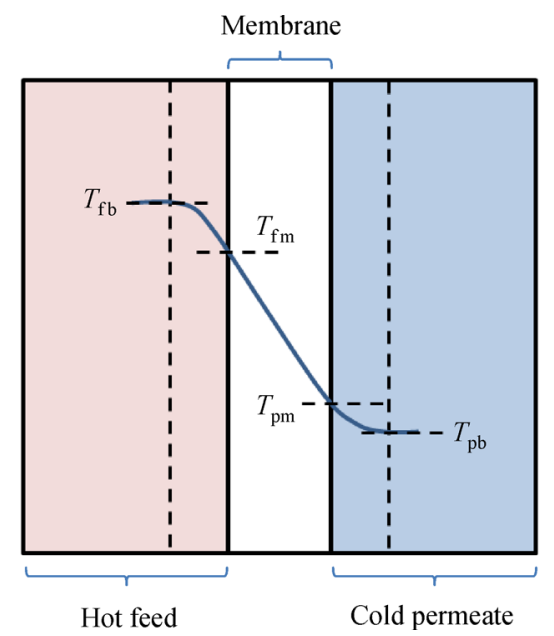

Fig. 1 A schematic representing the temperature profile across the membrane in MD. The four temperature positions shown are those required to calculate the TPC.

\subsubsection{Challenges}

Despite its many advantages, MD's industrial implementation is currently fairly limited. This is largely attributed to the high specific thermal energy requirements, relatively low fluxes and membrane wetting (caused by fouling, scaling or unsuitable process conditions). Improvements in thermal efficiency have been demonstrated by using novel membrane configurations (such as conductive-gap MD) or by employing internal latent heat recovery using spiral wound or multi-effect modules. In addition, heat integration with existing processes shows great potential to significantly reduce the produced water costs in MD and offer lower capital and operating costs than existing distillation processes [37]. However, increasing membrane fluxes and improving resistance to fouling requires design modifications at the level of the membrane itself [38].

In these regards, carbon nanomaterials have been highly effective, as this review will elucidate. In addition, they have been used to impart novel functionalities such as capacitive fouling-detection and localised heat generation through the joule effect, opening new possibilities for reducing operational costs and energy consumption. Despite concerns about the detrimental effect that thermally conductive carbon nanomaterials like graphene and carbon nanotubes (CNTs) may have on temperature polarisation, the evidence suggests that the typically low loadings used in membrane modification result in benefits that outweigh and, in some cases, even reduce this effect. This will be discussed in more detail later.

There have been a number of successful pilot studies conducted which demonstrate the feasibility and reliability of MD and a handful of companies are now manufacturing systems to address a variety of water challenges across the world [39-41]. With the combination of efficient modules, optimised process conditions and high-performance membranes, the future for MD looks bright. We refer the reader to a comprehensive review on opportunities and challenges for improving MD membranes and system design by Deshmukh et al. [42].

\subsection{Carbon nanomaterials}

Carbon nanomaterials make up an intensively studied and commercially valuable class of materials which are used in applications as wide reaching as energy production and storage [43], electronics [44], biomedical [45], composites [46], water purification [47] and others [48,49]. The discovery of fullerene in 1985, CNTs in 1991 and graphene in 2004 [50] show remarkably rapid progress in our ability to understand, synthesise and exploit these materials. Their discovery represents a significant part of the growing portfolio of nanomaterials and nanofabrication techniques that promise to revolutionise technology in the near future. Amongst the most significant emerging applications of 
these nanomaterials is in separation and purification technology, not least because globally, industrial separation processes account for a staggering $10 \%-15 \%$ of the world's energy use [51].

\subsubsection{Structure}

The carbon atom, with its electronic structure of $1 \mathrm{~s}^{2} 2 \mathrm{~s}^{2}$ $2 \mathrm{p}^{2}$, can exist in a variety of forms or allotropes, as shown in Fig. 2. When the outer orbitals undergo $\mathrm{sp}^{3}$-hybridisation, the resulting tetragonal structure gives rise to a hard, transparent, thermally conductive, electronically insulating material: diamond. Whereas, the $\mathrm{sp}^{2}$-hybridised bonding structure can result in the layered material known as graphite, a soft, opaque, thermally and electronically conducting material whose layers are weakly stacked on top of each other by Van der Waals forces [52]. A single of these layers, graphene, is transparent (owing to its thickness), strong, flexible (out-of-plane), stiff (in-plane), and highly conductive due to the 2-dimensional gas of highly mobile massless Dirac fermions atop its surface [53]. Roll this material into a cylinder and the result is a carbon nanotube, a one-dimensional quantum wire with similar strength to graphene which can be either semiconducting or metallic, depending on its chirality [54]. When $\mathrm{sp}^{2}$ and $\mathrm{sp}^{3}$ bonds are both present, carbon can adopt a football-like form known as fullerene (or a buckyball) [55]. This is a zero-dimensional quantum dot which can be synthesised in a great variety of sizes, containing different numbers of carbon atoms. Euler's theorem for simple polyhedra requires there to be no less than 12 pentagons in any fullerene structure with $\mathrm{C} 60$ being the smallest one possible (12 pentagons +20 hexagons). These electronaccepting nanomaterials have been widely explored for photovoltaic and fuel cell applications [56,57].
Carbon can also exist without long-range order as shown in Fig. 2(d). So-called amorphous carbon is present in substances such as coal and soot and can be characterised in terms of the proportion of $\mathrm{sp}^{3}$ and $\mathrm{sp}^{2}$ bonds in its structure. It is just one member of a family of disordered carbons which includes glassy carbons, activated carbon and carbon fibre which are widely used in applications such as water purification and aerospace [58].

\subsubsection{Properties}

The many forms that carbon can take give rise to a wide array of physico-chemical properties which can be exploited. In composite applications for example, the low dimensionality and high specific surface area of fullerene, nanotubes and graphene can cause dramatic property enhancements at relatively low loadings, provided a good dispersion is formed and agglomeration of the nanomaterial is prevented. Chemical functionalisation of these materials is a common approach to modifying their properties, improving matrix interaction and solution processability as well as enabling large-scale production [59].

A notable example of this is the oxidised form of graphene (graphene oxide or GO) which has been widely studied for membrane applications due to its hydrophilic nature. When single layers of GO are restacked into a planar structure, the oxygen groups on the surface and edges of the flakes produce a network of capillaries which allow water to flow almost without impediment whilst blocking divalent ions and larger molecules. While these unusual properties of $\mathrm{GO}$ have been reported by various independent research groups [60-63], the exact behaviour of water inside the nanochannels is still not fully understood. Efforts to model the system have typically (a)

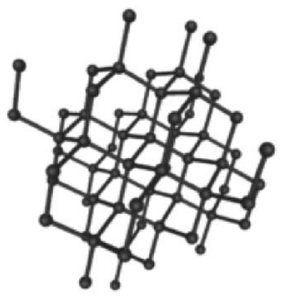

(b)

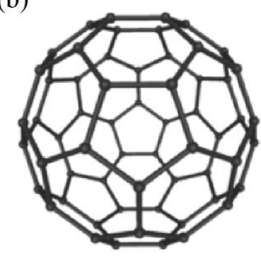

(c)

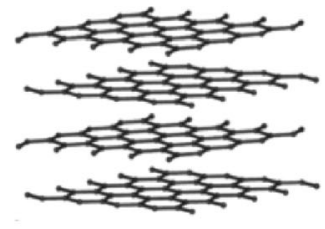

(d)

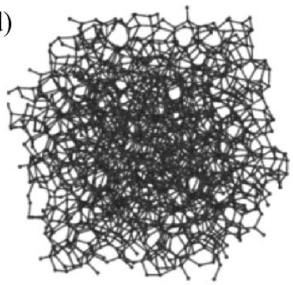

(e)

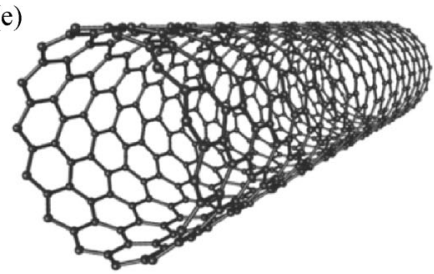

Fig. 2 The structures of the five main carbon allotropes: (a) diamond; (b) fullerene; (c) graphite; (d) amorphous carbon; and (e) carbon nanotube (modified under the Creative Commons license, Wikipedia website). 
simplified the structure of GO down to a single graphene capillary. Molecular dynamics simulations of such a simplified system have shown that the small interlayer spacing between the graphene sheets exerts a very high pressure (ca. $1 \mathrm{GPa}$ ) on the water molecules, leading to nanoconfinement [64]. This condition can result in the coordinated motion of the polar water molecules and, when coupled with the remarkable slip at the atomically smooth graphene interface, it can give rise to a significant flow enhancement factor of 100-1000 compared to conventional non-slip Poiseuille flow [65].

There have been similar observations made of radiusdependent water flow enhancement through CNTs although there are disagreements over the degree of flow enhancement and the underlying mechanisms $[66,67]$. The role of electronic structure was also reported to be significant by Secchi et al. who experimentally measured significant slip in CNTs but not in boron nitride nanotubes despite their crystallographic similarity [68].

Other properties of carbon nanomaterials include high strength, high electrical conductivity and broadband absorbance. This has enabled their use as composite fillers for strengthening polymers, as sensors for the detection of gases or foulant particles and even as self-heating coatings via the photothermal effect. Because of the great variety of properties that this class of nanomaterial exhibit, it is possible to use them to solve multiple engineering challenges at once. This principle applies to membranes as much as anywhere else, as will be evidenced in the following section.

\section{Applications of carbon-based nanomater- ials in MD}

\subsection{Modelling of graphene in MD}

While there have been many efforts to model the behaviour of water permeation through graphene and related nanostructures (i.e., CNTs), modelling the transport of vapour has proven difficult due to the high computational intensity of modelling phase changes. Zhang et al. [69] utilised coarse-grained molecular dynamics to model the MD process through graphene channels. The system was modelled by defining two vertically-stacked graphene unit cells placed between two water reservoirs with two perpendicular graphene pistons defining the outer boundary of the reservoir, as shown in Fig. 3. This system was based on the combined phenomena of evaporation and vapour transport as shown in Figs. 3(b) and 3(c). In real $\mathrm{MD}$, a third component is needed to fully describe the mass transport, namely the condensation on the permeate side. However, the effect of this process is much less significant than the other two and was neglected in this study.

In the evaporation model, an acceleration region was added to ensure any evaporated water molecules were carried away towards the permeate side. The feed side was thermostatted from $300 \mathrm{~K}$ to $360 \mathrm{~K}$ while the permeate reservoir was kept at $300 \mathrm{~K}$. They reported high distillation fluxes at channel spacings of between $2-5 \mathrm{~nm}$ within which a transition in the transport mechanism occurs between surface diffusion $(2 \mathrm{~nm})$ and Knudsen diffusion (3-5 nm). This transition resulted in a reduction in the lateral velocity of the water molecules due to increased wall-collisions which reduced the overall flux. Contrary to what is commonly reported for MD, the highest flux was observed for the smallest channel opening $(2 \mathrm{~nm})$ with a value of $10000 \mathrm{~L} \cdot \mathrm{m}^{-2} \cdot \mathrm{h}^{-1}(\mathrm{LMH})$ (three orders of magnitude higher than experimentally measured in conventional membranes). This was attributed to both: 1) the water transport being dominated by surface diffusion, and 2 ) the increased evaporation rate due to the higher number of water molecule collisions as a result of their strong interaction with the graphene. While the authors recognise the highly idealised conditions (i.e., no presence of trapped air in the pores, no consideration for temperature

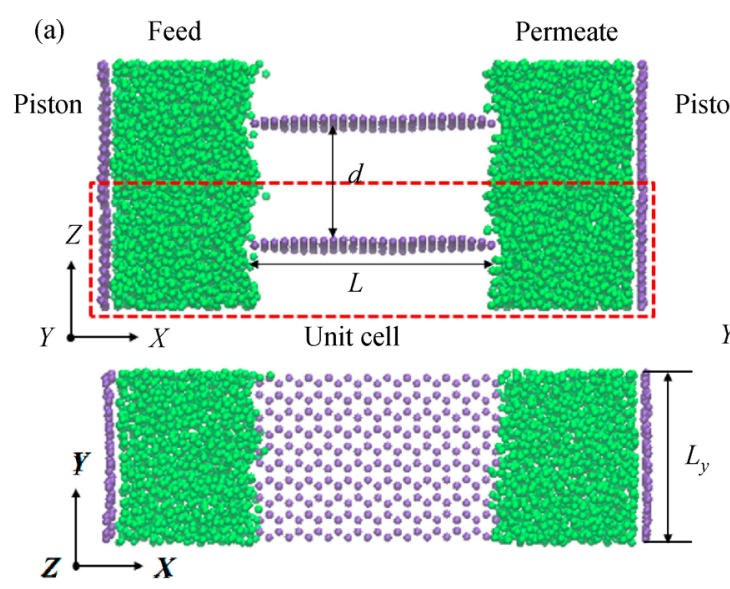

(b)
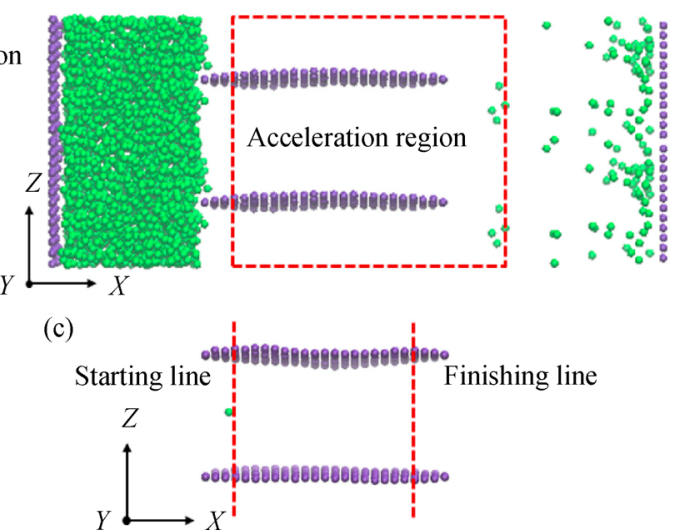

Fig. 3 The molecular dynamics simulation schematics of (a) the MD model, (b) the evaporation model and (c) the vapour transport model. Reprinted with permission from ref. [69]. Copyright 2018, Elsevier. 
polarisation and the absence of salt ions in the water), experimental evidence of significantly enhanced vapour permeation rates (ca. $10^{7} \mathrm{~g} \cdot \mathrm{m}^{-2} \cdot \mathrm{d}^{-1}$ or $417 \mathrm{LMH}$ at $25^{\circ} \mathrm{C}$ and relative humidity of $35 \%$ ) through atomically-thin graphene membranes has been provided elsewhere [70]. These results suggest that there are opportunities to further improve the flux values and the efficiency of MD by exploiting the unusual phenomena observed in nanoconfined water and through the use of ultrathin, low dimensional membranes.

The following sections describe the most recent uses of carbon nanomaterials in MD with a summary of the key information presented in Table 1.

\subsection{Mixed matrix membranes}

Mixed matrix membranes are defined as those in which a solid phase (such as a nanomaterial) is incorporated into a matrix material (such as a polymer). This approach is often achieved by blending the solid phase into the starting dope solution prior to membrane fabrication. As such, it can be a relatively straightforward way of imparting beneficial properties of the solid phase into the final membrane. Two of the most common membrane fabrication techniques used in MD are discussed here: phase inversion and electrospinning. In both cases, the effects of adding carbon-based nanomaterials into the membrane are evaluated.

\subsubsection{Phase inversion}

Phase inversion is a process that induces porosity into films or cylindrical jets of homogeneous polymer solutions. It was first developed by Loeb and Sourirajan [71] in the 1960s using cellulose acetate as the casting solution but is applicable for most polymers which can be dissolved into homogeneous solutions. The process typically requires just three components: a polymer, a solvent and a coagulation medium (or non-solvent). First, the polymer is dissolved into the solvent to form the casting solution. Then the casting solution is either spread using a doctor blade into a thin film (in the case of flat sheet or spiral-wound membranes) or spun into a cylindrical fibre (in the case of tubular or hollow fibre membranes). The final step is to bring the newly cast polymer solution into contact with the non-solvent, such as water, in a coagulation bath. This initiates the solidification of the polymer as the solvent in the casting solution is displaced by the non-solvent in the coagulation bath. The inter-diffusion of the solvent and non-solvent create heterogeneities within the casting solution, i.e., some regions rich in polymer and some regions deficient in polymer. The polymer-lean regions form the pores of the membrane and the polymer-rich regions continue to solidify and make up the pore walls. It is also possible to initiate the solidification process using a non-solvent which is in the vapour phase, or indeed with temperature-controlled evaporation whereby the polymer solution itself contains a mixture of a volatile solvent and a less volatile non-solvent (the latter becoming enriched over time as the former evaporates more readily) [71]. The solidification process can occur within seconds (as for the immersion precipitation method) or over several hours (as for the vapour-induced approach) [72,73] and, depending on the initial casting conditions and polymer solution composition, the resultant membrane can either have a symmetric or asymmetric structure. A symmetric structure is characterised by having little variation in the pore size throughout the membrane's cross section and can be readily obtained by using vapour as the non-solvent medium. A membrane with an asymmetric structure, on the other hand, is characterised by a dense 'skin' top layer containing small pores supported by a highly porous substructure containing larger pores or macrovoids. This structure is much more common for membranes prepared by immersion precipitation in a liquid non-solvent bath and can provide excellent filtration performance due to the top selective layer being very thin while the supportive layer increases the overall mechanical strength of the membrane [74].

This process is used to fabricate membranes for a range of applications, ranging from protein separations, dye removal, wastewater treatment and many others. Its use for MD membranes has been widely reported in the literature, mostly using polyvinylidene fluoride (PVDF) as the main matrix constituent although a great variety of polymers can be utilised in this technique. Work done by Woo et al. showed a near doubling of the water vapour flux when graphene nanoplatelets incorporating (GNPs) into a PVDF membrane via phase inversion [75]. The composite membranes were used to treat RO brine from coal seam gas produced water with AGMD. GNP quantities ranging from 0.1 to $2 \mathrm{wt}-\%$ (of the whole solution) were added with the best results coming from the $0.5 \mathrm{wt}-\%$ sample. Not only had the overall flux from this membrane increased from 11.6 to $20.5 \mathrm{LMH}$, but the long-term stability was drastically improved as a result of the prevention of fouling by salt crystals, which the pure PVDF membrane suffered from. The average pore size of these membranes increased from 60 to $110 \mathrm{~nm}$ with the addition of GNP and the overall porosity also increased from $78.2 \%$ to $84.7 \%$. It is these characteristics to which the flux increase is attributed, along with the increased water contact angle as a result of graphene's hydrophobicity. Higher GNP quantities resulted in a further increase in the water contact angle and a reduction in their porosity, possibly due to graphene agglomeration, which reduced the flux. Also, the membranes with higher GNP concentrations were slightly thicker than those without, which reduced the mass transfer resistance. Nevertheless, the 2 wt-\% GNP membrane still showed a $40 \%$ increase in flux compared to the pure PVDF 


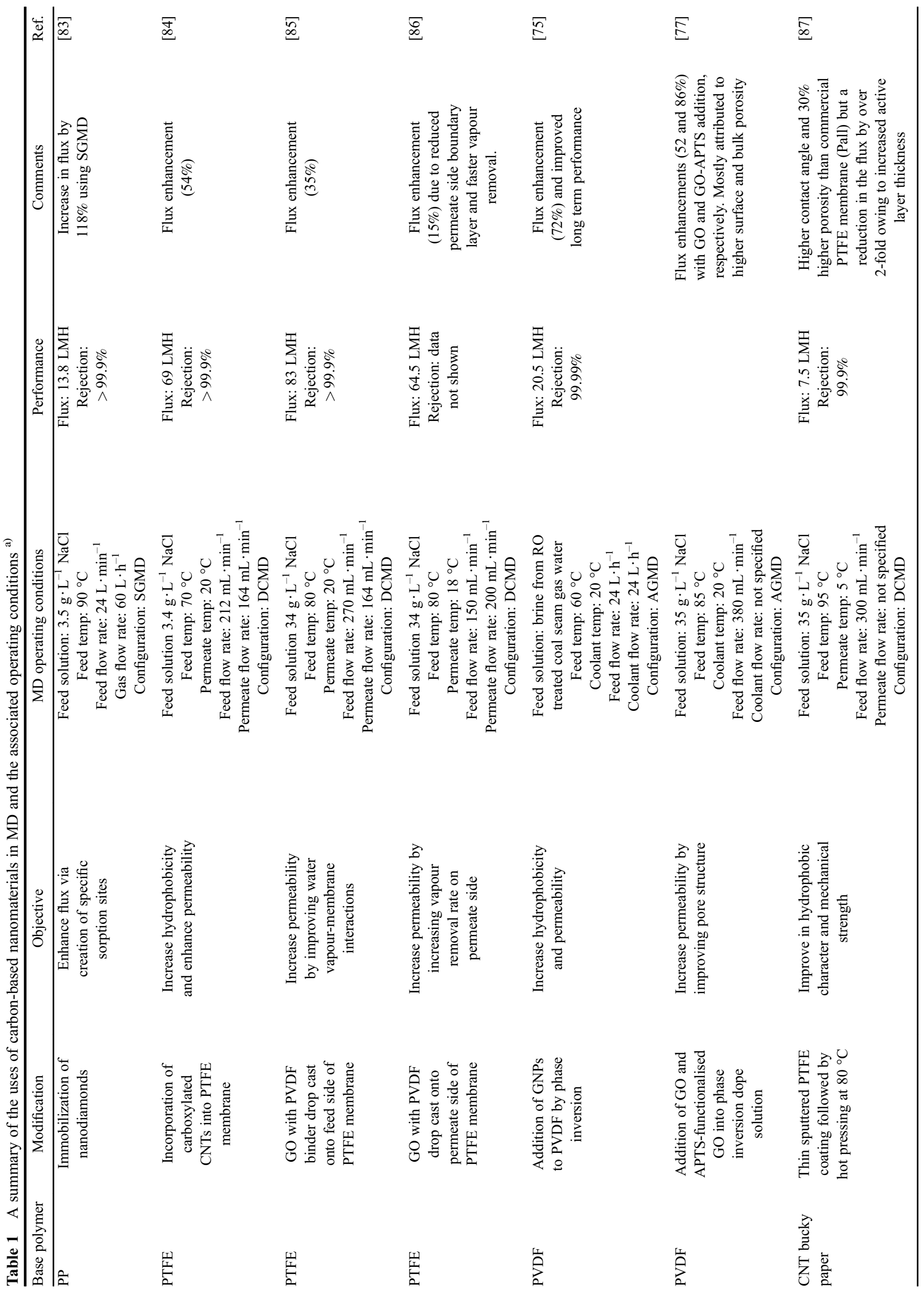




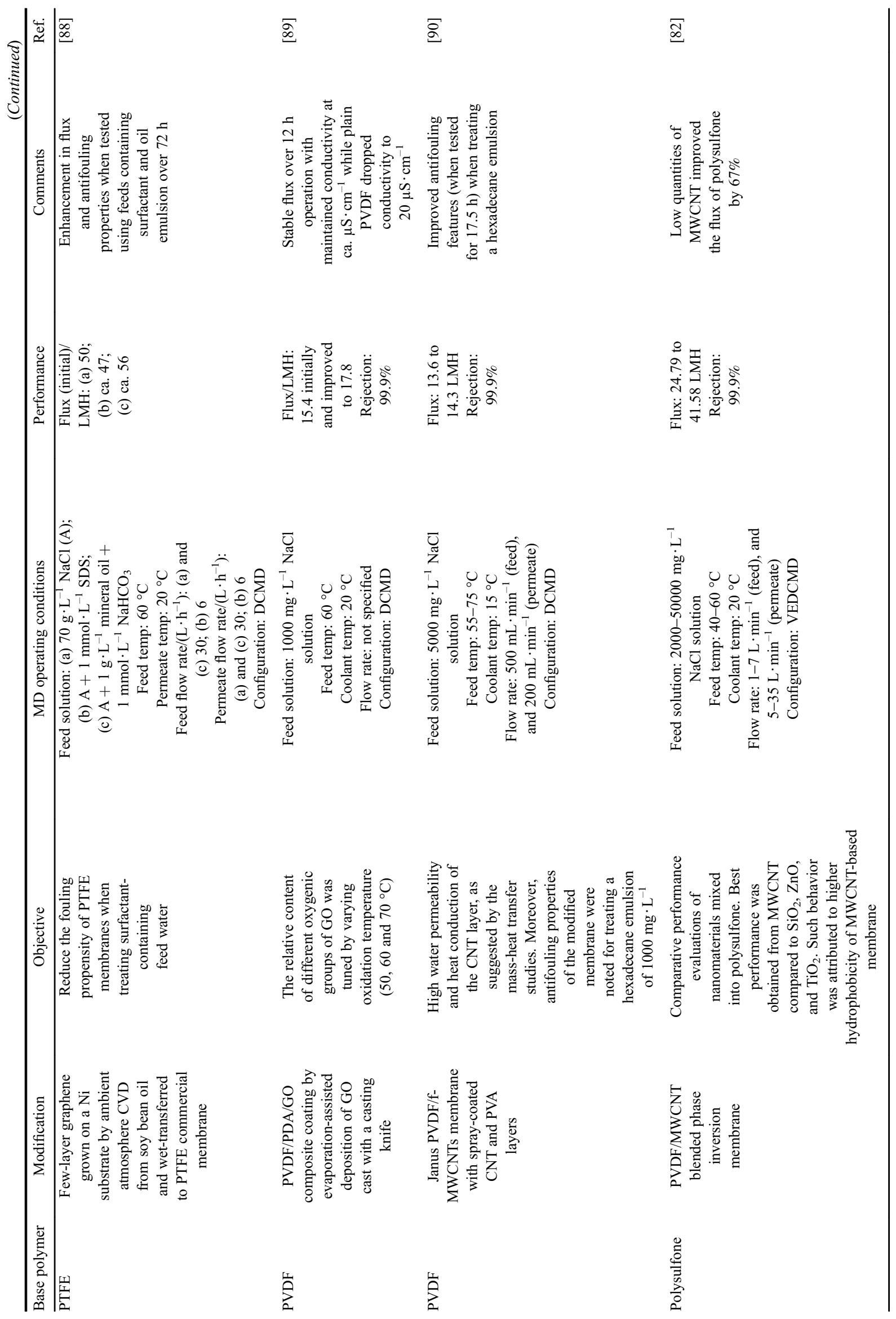




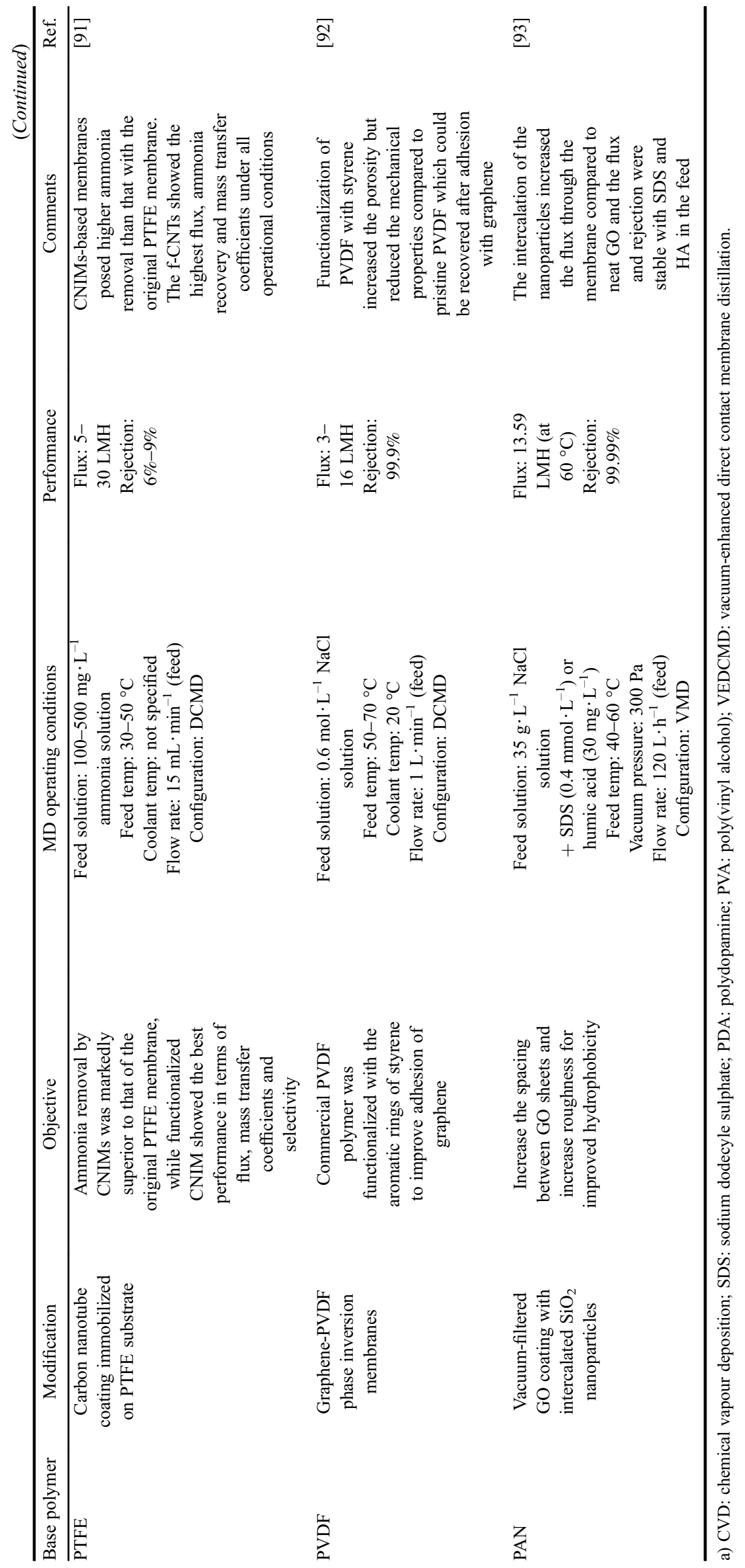


membrane despite being $18 \%$ thicker and having almost identical porosity [75].

Similar results were obtained by Athanasekou et al. [76], who blended graphene functionalised with benzoic acid into a PVDF mixed matrix membrane. They also investigated a novel technique of using an aqueous suspension of GO as the coagulation medium for PVDF dope solutions to produce a coating on the membrane. Optimal microscopy and micro-Raman analysis were used to show the presence of the nanomaterials in/on the membranes in both cases. For the graphene membranes, an optimum loading of 0.87 wt- $\%$ (w.r.t. PVDF) increased the membrane porosity modestly from $70.1 \%$ to $73.8 \%$, yet resulted in a $1.7 \times$ increase in flux compared to the neat PVDF membrane and achieved $99.8 \%$ salt rejection. At higher loadings, the flux fell to below that of the PVDF membrane, in agreement with other studies discussed in this review. They used the isostrain and Maxwell models to investigate the effect of graphene addition to the thermal conductivity of the membranes and the membrane/water vapour system. Unsurprisingly, the thermal conductivity of the solid membrane increased substantially (15.7\%) at the highest graphene loading of $6.25 \mathrm{wt}-\%$, which gave rise to an even more significant change in thermal conductivity for the membrane/vapour system (an increase of $58.4 \%$ compared to the pure polymer). However, at lower loadings this change was minimal and for the $0.87 \mathrm{wt}-\%$ loading, the conductivity of the membrane/vapour system actually decreased by $6.8 \%$ due to the increased porosity. The smoother surface of this membrane, as shown by atomic force microscopy, resulted in reduced scaling by $\mathrm{CaCO}_{3}$ compared to the neat PVDF membrane, which was evidenced by more stable flux values. The GO membranes however, exhibited pore wetting and low salt rejection $(80 \%)$ owing to the greater hydrophilicity of the surface.

In our earlier work we compared the performance of PVDF mixed matrix membranes incorporating GO and GO functionalised with (3-aminopropyl)triethoxysilane (APTS) for desalination of artificial seawater using AGMD [77]. We found that the addition of small quantities of both nanomaterials increased the surface porosity and mean pore size. The best performing membranes achieved $52 \%$ and $86 \%$ flux enhancements for GO and GO-APTS membranes, respectively compared to the pure PVDF membrane. At higher loadings however, the rejection performance declined slightly for the GO membrane, due to increased hydrophilicity and larger pore size but remained above $99.9 \%$ for all GO-APTS membranes. It was suggested that the interactions between the nanofiller and the polymer solution increased the rate of interdiffusion between the solvent and non-solvent during the phase inversion process. This in turn resulted in higher porosities and a less dense pore structure which gave rise to higher flux values.

We later investigated using reduced $\mathrm{GO}(\mathrm{rGO})$ with different degrees of reduction to see how this affected the membrane morphology and performance, using XPS to quantify the reduction degree [78]. As the carbon to oxygen $(\mathrm{C} / \mathrm{O})$ ratio of the $\mathrm{GO}$ flakes increased from 2.30 (for $\mathrm{GO}$ ) to 5.45 (for rGO), the measured flux increased from 6.4 to $7 \mathrm{LMH}$ and the permeate conductivity reduced significantly from 643 to $41 \mu \mathrm{S} \cdot \mathrm{cm}^{-1}$, indicating improved wetting resistance. However, at a higher degree of reduction $(\mathrm{C} / \mathrm{O}=7.36)$ the flux dropped to $3.9 \mathrm{LMH}$, indicating less favourable pore-forming characteristics with the further removal of the oxygen functionalities. This pore-forming behaviour of GO materials has been reported elsewhere [79], and has been shown in some cases to not only increase the porosity and improve the pore structure of the membranes, but also to improve the mechanical properties at the same time due to the nanomaterial's high strength and good interaction with the matrix material [80].

Morphological reasons alone are not always responsible for improved performances of mixed matrix membranes. Ragunath et al. [81], for example, incorporated multiwalled CNTs (MWCNTs) in a PVDF polymer membrane which was cast onto a polypropylene (PP) support membrane and again fabricated via phase inversion. The best membrane exhibited a flux of 51.4 LMH, representing a $76 \%$ increase compared to the support membrane, using DCMD at $80^{\circ} \mathrm{C}$. The calculated mass-transfer coefficient was 1.8 times higher for this membrane than the unmodified membrane despite there being no significant differences in their porosity or mean pore size. In addition to making the membrane more hydrophobic, as shown by increases in the water contact angle, it was suggested that the CNTs provide additional pathways for vapour diffusion.

Finally, Fahmey et al. compared different nanoparticles (MWCNT, $\mathrm{SiO}_{2}, \mathrm{TiO}_{2}$, and $\mathrm{ZnO}$ ) as additives in polysulfone mixed matrix membranes [82]. While all optimised membranes achieved high salt rejection (99.9\%), they found the MWCNTs provided the best performance in terms of flux (41.58 LMH), followed by $\mathrm{SiO}_{2}$ (38.84), $\mathrm{TiO}_{2}$ (35.6) and $\mathrm{ZnO}(34.42 \mathrm{LMH})$ with optimized concentrations of $1.0,0.5,0.75$, and $0.5 \mathrm{wt}-\%$, respectively, relative to the polymer weight of $15 \%$. These results were obtained using $\mathrm{NaCl}$ feed water $\left(10000 \mathrm{mg} \cdot \mathrm{L}^{-1}\right)$ with feed and permeate temperatures of $60{ }^{\circ} \mathrm{C}$ and $20^{\circ} \mathrm{C}$, respectively. The higher performance of the MWCNT membrane was attributed to higher porosity and hydrophobicity than obtained by the other nanoparticles.

\subsubsection{Electrospinning}

Electrospinning, a portmanteau of 'electrostatic spinning', is a simple method of producing nanofibres from a wide range of polymeric and ceramic materials for various applications. Whilst it is considered a fairly modern 
fabrication method, the basic process was outlined in a series of patents by Anton Formhals as early as 1934 [9497]. Just three components make up the necessary equipment for electrospinning: a high voltage power supply, a spinneret and a conductive collector. First, a solution (or melt) of the desired material (in this case, consider a polymer such as PVDF) is inserted into the spinneret (for lab-based setups, this is typically a syringe with a metallic needle attached). Then a potential is applied across the spinneret and the conductive collector (typically in the range of $10-40 \mathrm{kV}$ ). The syringe is then slowly pressed with a pump or an actuator and the solution is then rapidly drawn into tiny fibres that travel across the electric field from the spinneret to the collector. This happens when the electrostatic forces which build up on the surface of the polymer solution overcome the solution's surface tension and form a Taylor cone. As the electrically charged jet of material travels towards the grounded collector it rapidly bends and whips, undergoing significant stretching. This process can reduce the fibre cross section by up to six orders of magnitude, resulting in nanofibers which are just tens of nanometers across $[98,99]$. Meanwhile, the solvent evaporates and the polymer begins to solidify. It is possible to control the morphology of the nanofibers by adjusting parameters such as solution viscosity, applied voltage, tip to collector distance, solvent volatility and others. Furthermore, it is possible to produce randomly oriented fibres by using a flat stationary collector, or highly aligned fibres by use of a rotating collector drum. The former has been increasingly utilised for the fabrication of membranes for MD. The high surface roughness, hydrophobicity, high porosity and interconnected pore structures of membranes produced in this way make them highly competitive with and often superior to current state of the art materials for MD applications [100,101].

As with the membranes produced via phase inversion, those produced by electrospinning can exhibit enhanced characteristics with the addition of nanomaterials to the starting polymer solution. Woo et al. incorporated GNPs into electrospun PVDF-co-hexafluoropropylene nanofiber membranes and achieved a $34 \%$ increase in LEP, a $51 \%$ increase in tensile strength and an $83 \%$ increase in vapour flux compared to the pure polymer sample, whilst maintaining $100 \%$ salt rejection [102]. In this case the optimal quantity of graphene was fairly high $(5 \mathrm{wt}-\%)$ but the increased electrical conductivity in the polymer solution as a result of this loading improved the formation of nanofibers due to enhanced electrostatic forces. The increase in the LEP of these membranes was attributed to both the intrinsic hydrophobicity of graphene and also the increased surface roughness caused by flakes protruding out of the nanofibers, as shown in Fig. 4. The increase in tensile strength was attributed to strong interaction between the graphene and the polymer as well as good interconnectivity between the fibres. Whilst high mechanical strength is not considered a crucial property of MD membranes (due to the low-pressure nature of the process), it is a non-trivial consideration when using the electrospinning technique. Conventional methods of improving the mechanical properties of electrospun materials have been to either increase the spinning time (and therefore the thickness of the material) or to utilise a post-treatment step such as hot pressing or solvent evaporation which fuses the overlapping regions of the fibres and prevents the delamination or disintegration of the structure. For the use of membranes, both of these approaches compromise the overall efficacy of the technique. In the first case, the hot (or cold) pressing of the material necessarily compacts the structure, thereby reducing the porosity and increasing the mass transfer resistance. In the second case as well as the first, the additional processing step adds complexity (and cost) to the overall process. The use of graphene in this way is a good example of exploiting its multiple properties to solve multiple problems simultaneously: its high electrical conductivity promotes the formation of (desirably) small nanofibers, its intrinsic hydrophobicity along with the nanoscale roughness it imparts to the fibres increases the wetting resistance of the membrane while its high mechanical strength eliminates the need for a posttreatment step. It also improves the thermal stability of the membrane, which is another important consideration for the long-term operation of MD.
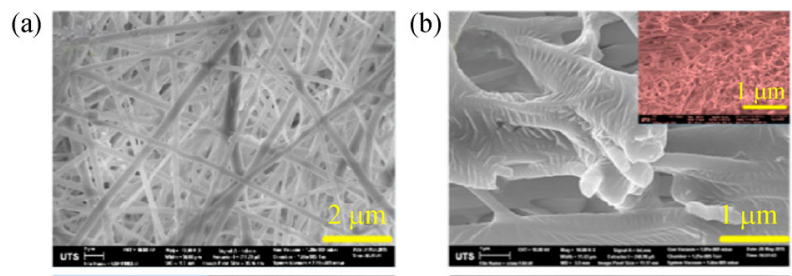

(c)
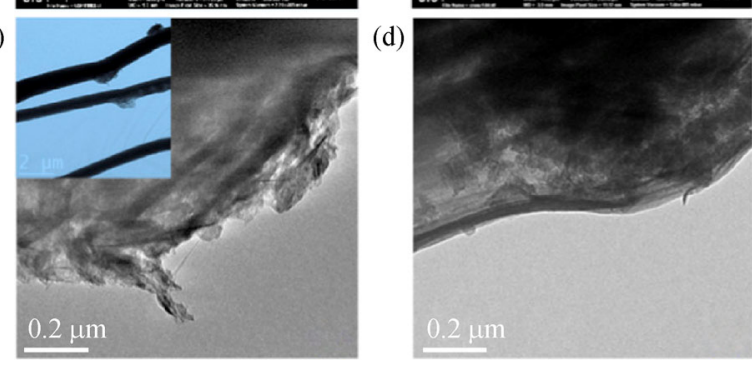

Fig. 4 (a) Surface and (b) cross-sectional scanning electron microscopy images of graphene/electrospun nanofiber membrane; (c) and (d) transmission electron microscopy images of the same membrane. The protrusions of graphene through the fibres provide nanoscale roughness which increases the membrane hydrophobicity. Reprinted with permission from ref. [102]. Copyright 2016, Elsevier.

The same group also used this approach to incorporate CNTs into electrospun membranes which created a beaded fibre morphology resulting in superhydrophobicity [103]. They also suggested that CNTs, which also protruded from the polymer beads, facilitated active diffusion of water 
vapour through the membrane, contributing to the flux enhancements. Lee et al. suggested that the observed flux enhancements of CNT-nanofibre membranes could be explained by the combination of improved heat transfer (due to increase surface roughness) and higher mass transfer due to slightly increased porosity and pore size as well as the increased hydrophobicity of the pore walls which enabled greater slip conditions for vapour diffusion [104]. Only when the effects of these various mechanisms were combined could their model successfully predict the observed experimental data.

The wetting resistant and antimicrobial properties of CNT-silica composite membranes was demonstrated by Sun et al. [105]. They used CVD to grow vertically orientated CNTs on an electrospun silica fibre mat. The superhydrophobic structure exhibited water-in-air and oilin-water contact angles of $129.1^{\circ}$ and $169.4^{\circ}$, respectively, in dramatic contrast to the hydrophilic silica fibre mat. They reported improved flux stability and rejection performance of this membrane compared to a commercial PVDF membrane when mineral oil was added to the saline feed water $\left(80 \mathrm{mg} \cdot \mathrm{L}^{-1}\right.$ mineral oil in $\left.1.0 \mathrm{~mol} \cdot \mathrm{L}^{-1} \mathrm{NaCl}\right)$. The vertically protruding CNTs trapped a layer of air in the surface of the membranes, reducing the wetting propensity. This effect was particularly noticeable when using longer nanotubes. Furthermore, this membrane exhibited ca. $80 \%$ reduction in biofouling (by Escherichia coli) compared to a control membrane, attributed to the rough surface produced by the tube tips which create a barrier to cell deposition.

It should be noted that while the use of electrospinning for membrane applications is increasingly evident in the literature, it is still relatively expensive to scale up in comparison to conventional methods like phase inversion. Currently its primary uses remain in biomedical applications for which the cost-benefit is proven. However, certain innovations such as the use of a rotating perforated ball in place of multiple syringe heads (as developed by the Stellenbosch Nanofiber Company [106]) are addressing these problems and so demand for nanofiber membranes will probably grow in future.

Other widely used materials for MD membranes are polypropylene (PP), polyethylene and polytetrafluoroethylene (PTFE). These are also more expensive to produce, since they are not readily dissolved in solvents and so can't be fabricated by phase inversion. Instead, these materials undergo complex stretching and annealing processes in order to induce porosity. Despite this, their low surface energies and high thermal and chemical stabilities make these two materials very attractive for MD applications [107].

\subsection{Coatings}

Perhaps a more obvious approach to using carbon nanomaterials for MD applications is as a coating. Indeed, some of the first work on GO membranes was utilising a thin laminated coating which sat on top of existing porous membranes to provide a selective yet highly permeable top layer [60]. In the case of MD, the need for a speciesselective layer is largely removed by the fact that separation occurs due to a phase change. Nevertheless, the special interactions between these nanomaterials and water have been shown to enhance the vapour flux whilst retaining high rejection when used as a coating on top of commercially available polymeric membranes.

\subsubsection{Flux-enhancing coatings}

Bhadra et al. have investigated a range of carbon nanomaterials as coatings on MD membranes. In one study, they coated the bore of a PP hollow fibre membrane with a solution of detonation nanodiamonds and PVDF in acetone in order to improve the flux and antiwetting property of the membrane [83]. They reported flux increases of up to $118 \%$ compared to the unmodified membrane using SGMD. The flux and high rejection (99.9\%) were stable for $90 \mathrm{~d}$ of treating artificial seawater (34000 $\mathrm{mg} \cdot \mathrm{L}^{-1} \mathrm{NaCl}$ ). Furthermore, this membrane was less sensitive to increases in the feed water salinity compared to the control membrane. This was attributed to activated diffusion of water which was facilitated by the nanodiamonds immobilised on the membrane surface and in the pores.

They also observed significant increases in flux when drop casting a GO layer (containing $2 \mathrm{wt}-\%$ PVDF as a binder) on top of a commercial PTFE membrane using a DCMD testing configuration [85]. Though the GOimmobilised membrane (GOIM) reduced the water contact angle from $110^{\circ}$ to $90^{\circ}$ and slightly increased the overall thickness of the membrane, the flux was improved by as much as $50 \%$ compared to the pristine PTFE sample. In addition, the effect of salt concentration on flux was significantly reduced for the GOIM, as observed with the nanodiamonds. When raising the salt concentration from 3500 to $34000 \mathrm{mg} \cdot \mathrm{L}^{-1}$, the flux for the unmodified membrane reduced by nearly $30 \%$ whereas for the GOIM, it reduced by less than $1 \%$. This result was attributed to various attributes of the GO layer, such as the nanocapillary effect allowing for rapid transport of water, polar functional groups acting as selective sorption sites for vapour and even reduced temperature polarisation due to the higher conductivity of the GO layer.

They reported similar results when incorporating carboxylated CNTs into the PTFE membrane [84]. Like the GO modified membranes, these exhibited a reduced water contact angle, yet the flux increased by as much as $54 \%$ and the stability with increased salt concentrations was significantly higher. It was again suggested that the CNTs provided adsorption sites for water vapour whilst rejecting the liquid brine. This effect was enhanced by the polarity of the carboxyl groups on the nanotubes and 
contributed to the flux increase, as suggested for the GO modified membranes.

A flux enhancement of $15 \%$ was reported in a separate work by Intrchom et al. who applied the same GO/PVDF coating mentioned above on the permeate side of the membrane rather than the feed side, again via drop coating [86]. It was said that the GO layer increased the removal rate of water vapour from the interface between the membrane and the permeate stream, effectively reducing the boundary layer between the liquid and vapour phases. This in turn increased the mass transfer coefficient and resulted in higher fluxes compared to the unmodified PTFE membrane. This increase was also stable for long testing periods $(60 \mathrm{~d})$, indicating that the GO layer was strongly attached to the membrane surface.

More recently, they compared GO with carboxylated CNTs as a coating on the membrane surface for the removal of methyl tert-butyl ether in sweep gas MD [108]. A flux enhancement of up to $22 \%$ was obtained with the CNT membrane and a rejection of $56 \%$ compared to $46 \%$ for the unmodified PTFE membrane. In most cases the flux and separation factor were highest for the CNT membrane and lowest for the control PTFE membrane, explained by the improved adsorption capacity of the carbon nanomaterials for methyl tert-butyl ether. The selectivity generally decreased with increasing temperature except for the GO membrane where it showed a positive trend, although an explanation for this was not given.

\subsubsection{Anti-fouling coatings}

The antifouling properties of GNP-coated polyethylene membranes were investigated in a study conducted by Mansour et al. [109]. The coatings were produced by vacuum filtration of GNP/ethanol solutions with concentrations ranging from 0.08 to $0.2 \mathrm{wt}-\%$. When weighing the membranes before and after immersing them for $10 \mathrm{~h}$ in distilled water, they found no evidence of the graphene leaching from the surface, suggesting good attachment. When treating real $\mathrm{RO}$ reject brine from a desalination plant, they found that the GNP coating reduced flux decline by up to $78 \%$ compared to the unmodified membrane. Even though the inclusion of GNP into the membrane's pores reduced the porosity from $89.4 \%$ to $56 \%$ and the initial flux value from 30 to $15 \mathrm{LMH}$, the stability of the flux was greatly enhanced over a $10 \mathrm{~h}$ period. This corresponded to the GNP/ethanol concentration of $0.16 \mathrm{wt}-\%$ which also increased the contact angle and LEP and reduced the fouling propensity.

Quite a different coating approach was taken by Seo and co-workers who utilised an ambient-air CVD technique to grow few-layer graphene onto polycrystalline $\mathrm{Ni}$ foils using soy bean oil as the carbon source [88]. They deposited the graphene layer onto a commercial PTFE membrane by a wet-transfer process and then tested the membrane in DCMD. They used a variety of feed types, including real seawater, saline water containing the surfactant, SDS, and saline water containing an emulsion of mineral oil and sodium bicarbonate, which are well known to cause membrane fouling in MD due to hydrophobic interactions with the membrane surface. Not only did the graphene coated membrane show ca. $20 \%$ higher fluxes for real seawater compared to the pristine PTFE membrane, but the stability of the flux was also greatly improved over long testing times (up to $72 \mathrm{~h}$ ). It was found that fewer foulant molecules had attached to the graphene layer after testing and so the pore-blocking phenomenon was less severe than for the uncoated membrane. The interaction between the graphene and the SDS molecules were said to be of the weak physisorption type which has been exploited elsewhere for creating stable aqueous graphene inks [110,111]. This weak interaction could be easily overcome by the flow of the feed water in the membrane module and so membrane fouling was mitigated. This antifouling property has been described for graphene and GO elsewhere and is perhaps one of the most promising attributes of these materials for water treatment applications [112-114]. It was proposed that the water molecules permeated through overlapping grain boundaries, which had a calculated energy barrier, ca. $0.78 \mathrm{eV}$. This was easily overcome by the thermal energy input of the process so there was no need to engineer pores directly into the graphene, as has been achieved on small scales previously $[70,115,116]$. Finally, the presence of the CVD-grown graphene coating increased the temperature difference, $\Delta T$, across the membrane feed and permeateside surfaces, as depicted in Fig. 5. Whilst this was a subtle effect in this case, only raising the $\Delta T$ by $1-2{ }^{\circ} \mathrm{C}$, it does

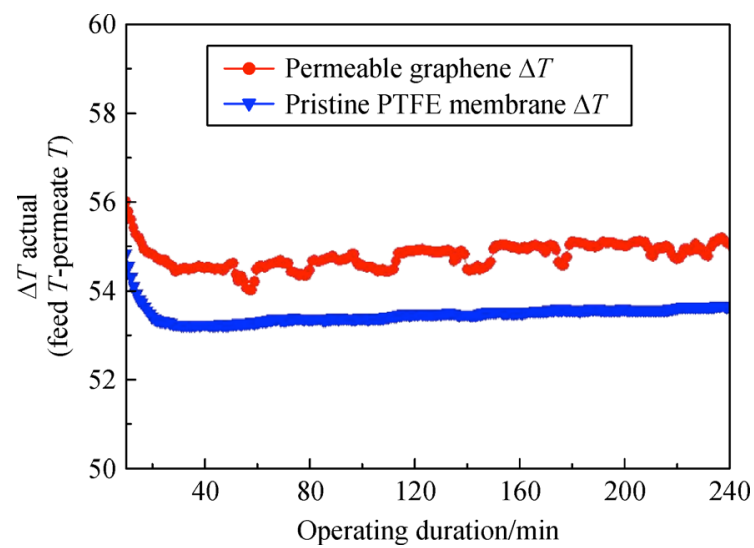

Fig. 5 The effect of the polycrystalline graphene coating on the PTFE membrane is shown here to increase the measured temperature difference across the feed and permeate side due to the high thermal conductivity of the graphene layer. The feed used here was a $70 \mathrm{~g} \cdot \mathrm{L}^{-1} \mathrm{NaCl}$ solution at a temperature $90{ }^{\circ} \mathrm{C}$ and the permeate stream was deionised water at $20{ }^{\circ} \mathrm{C}$. Reprinted with permission from ref. [88]. Copyright 2018, Nature. 
suggest that having a thermally conductive top layer may be desirable for MD applications and may reduce the degree of temperature polarisation as suggested by Bhadra et al. [85].

Following the approach commonly used to reduce fouling in membranes for pressure-driven applications, Nthunya et al. applied a thin hydrophilic coating on top of superhydrophobic PVDF nanofibre membranes modified with functionalised silica nanoparticles [117]. When treating real brackish water (total dissolved solids range $=9.176-25.412 \mathrm{~g} \cdot \mathrm{L}^{-1}$; total organic carbon range $=0.36-$ $\left.2.21 \mathrm{mg} \cdot \mathrm{L}^{-1}\right)$, severe flux decline $(62.1 \%-75.6 \%)$ was observed due to organic fouling of the uncoated membrane over $50 \mathrm{~h}$ of testing. The coating comprised of silver nanoparticles mixed with carboxylated MWCNTs in a 10 wt-\% PVDF solution, which was coated onto the nanofibre membrane and coagulated in a water bath. The flux decline was significantly reduced (26.6-33.5) while maintaining high rejection (ca. 99\%). While many approaches to reduce fouling in MD consist of increasing the antiwetting properties by increasing the membrane hydrophobicity, this work suggests that it is possible to still prevent significant wetting from occurring in MD while using thin hydrophilic coatings which are known to reduce the attachment of organic molecules present in certain water types.

\subsubsection{Electro- and photoactive coatings}

Carbon nanomaterials have also been successfully used for in-situ monitoring of fouling during MD tests. Ahmed et al. [118] coated filter paper with carbon nanostructures (comprised of entangled, covalently bonded CNTs) and fluorinated silica. This rendered the membrane both hydrophobic and electrically conductive. By using the membrane as an electrode and a stainless-steel counter electrode in the membrane cell, it was possible to measure changes in the capacitance caused by the attachment of foulant particles on the membrane surface. Such an approach, they note, could enable much greater optimisation of the operating conditions and cleaning regimes for large scale MD applications.

A few researchers have also looked at how carbon-based nanomaterials can be used to generate local heat on the membrane itself to drive the MD process. Recognising that heating large bodies of water in separate tanks or reservoirs requires a lot of energy, attempts have been made to heat only the water which is in direct contact with the membrane (and is therefore able to permeate through it as vapour). For example, Dudchenko et al. employed an electrically conductive CNT/PVA composite coating on a porous PTFE substrate which would generate local heat upon the application of a current due to the Joule effect [119], as depicted in Fig. 6.

By using an AC supply in which the voltage polarity was rapidly switched, the researchers were able to demonstrate stable Joule heating (up to $95{ }^{\circ} \mathrm{C}$ in air) without membrane degradation or water splitting occurring, as is common in ionisable media like salt water under high DC potentials [120-122]. They achieved fluxes of just over $8 \mathrm{LMH}$ with greater than $99 \%$ rejection and very high single-pass recovery values approaching $100 \%$. The energy consumption of the process was $1.12 \pm 0.01 \mathrm{kWh} \cdot \mathrm{kg}^{-1}$ when including heat recovery (or $1120 \mathrm{kWh} \cdot \mathrm{m}^{-3}$ ). This value is considerably higher than for most MD systems but optimising the configuration and

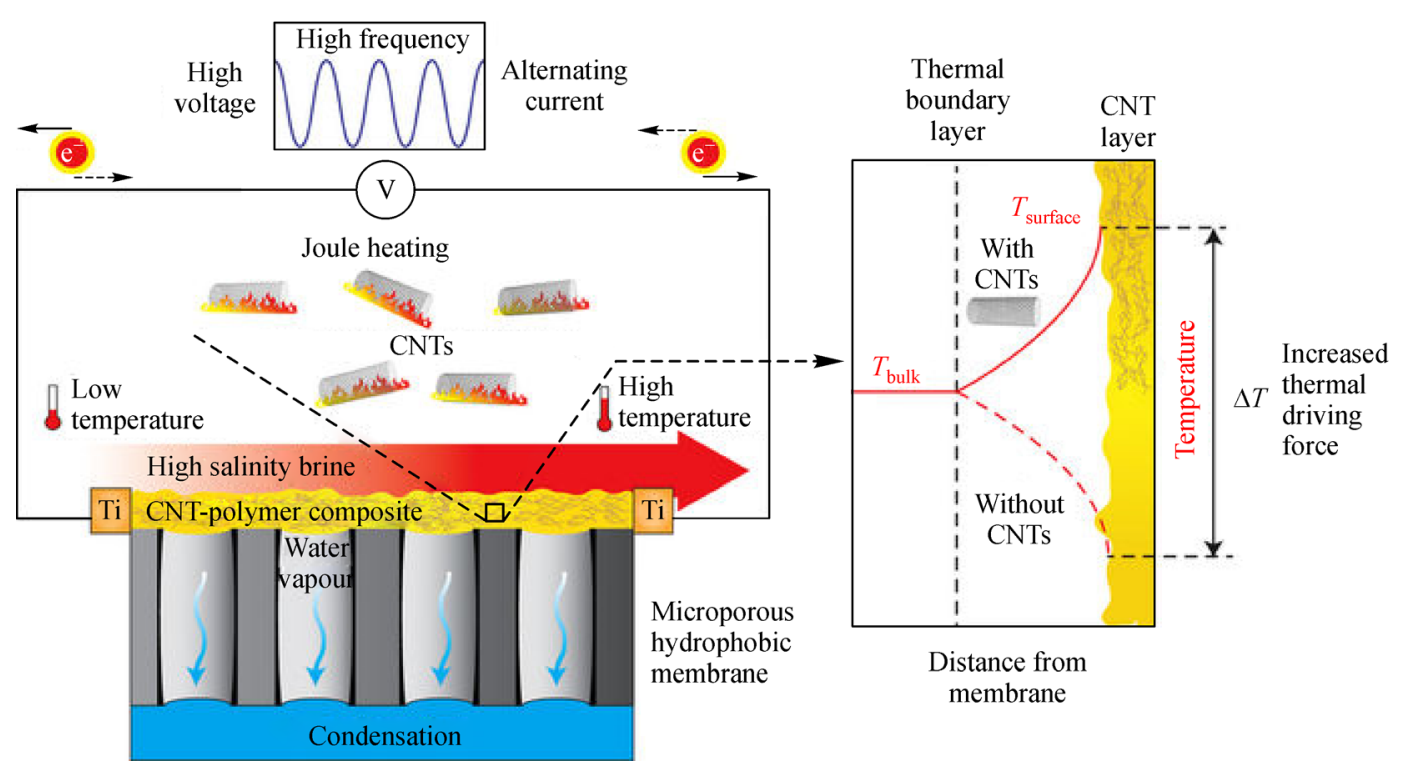

Fig. 6 Depiction of a CNT/PVA conductive coating which generated localised heat upon the application of a current as a result of the Joule effect. Reprinted with permission from ref. [119]. Copyright 2017, Nature. 
operating conditions, they say, could increase the feasibility of the process at scale. Using a different approach to achieve the same goal, Dongare et al. applied an electrospun carbon black/PVA coating on top of a PVDF membrane which could generate localised heat upon direct illumination with solar radiation as a result of the photothermal effect [123], as depicted in Fig. 7.

The broadband absorbance of carbon black makes it an efficient photothermal material for local heat generation [124]. This phenomenon has also been demonstrated in graphene and rGO, not yet for membranes, but for biomedical applications such as tumor treatment $[125,126]$. The temperature generated on the membrane (using real sunlight) reached ca. $35{ }^{\circ} \mathrm{C}$, representing an energy conversion efficiency of $53.8 \%$. However, this corresponded to a fairly low water flux of ca. 0.5 LMH. While the authors note the advantage of self-heating photothermal membranes having lower water flow requirements (since lower flow rates resulted in higher fluxes) and requiring less equipment for heating (such as solar thermal panels), it is not clear how the system could be effectively scaled up to allow for complete sun exposure to the membranes without requiring a correspondingly large footprint.

\section{Conclusions and future directions}

Many research efforts have shown that the use of carbon nanomaterials can improve the performance of MD membranes. The materials reviewed here include graphene, GO, CNTs, nanodiamonds and carbon black. Researchers have utilised these materials for different reasons and have demonstrated their efficacy in increasing membrane flux, reducing fouling propensity, improving mechanical properties, generating localised heat to drive the MD process and enabling in-situ monitoring of fouling. It is evident that these nanomaterials act as pore-forming agents in phase inversion membranes, giving rise to higher

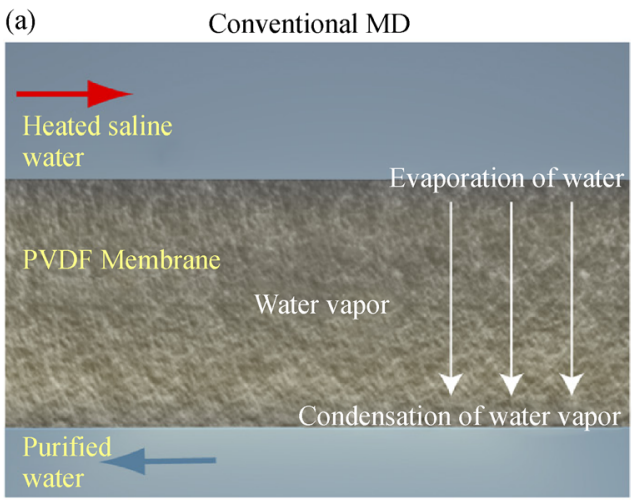

porosities and therefore higher fluxes, without compromising the mechanical properties (or even enhancing them). The hydrophobicity of these materials can also increase wetting resistance and reduce fouling when used as fillers or as a coating. In addition, the electronic properties can be used to turn the membranes into sensors which can create new opportunities for process optimisation by combining in-situ sensing data with analytical techniques such as machine learning. This, in turn, could be used to control automated cleaning processes and thereby lower operational costs.

At high loadings of thermally conductive materials such as graphene or CNTs, concerns arise due to increased temperature polarisation. However, at optimal loadings (which are typically $<1 \%$ ) this effect has been overcome by the beneficial effects they impart and in some cases, temperature polarisation was even shown to have decreased. These very low optimal loadings that have been observed are testament to the low dimensionality and high specific surface area of these nanomaterials. This is beneficial from a cost-perspective, where a need for high weight percentages of such nanomaterials would likely be economically unviable for high volume products like filtration membranes.

The development of high flux membranes can increase the productivity of MD and provided that the latent heat is recovered in the system, this higher rate of mass transfer will not jeopardise the thermal efficiency. By developing a more complete understanding of the behaviour of nanoconfined water in small carbon capillaries, it may be possible to make breakthroughs in evaporation efficiency and vapour transport that could enhance the overall performance in MD. Modifications to module and system design have proven successful at increasing the thermal efficiency of the process and continuation in this direction is recommended in parallel with more of a focus on other membrane properties such as long-term fouling resistance, response to cleaning protocols and simplicity of fabrication.

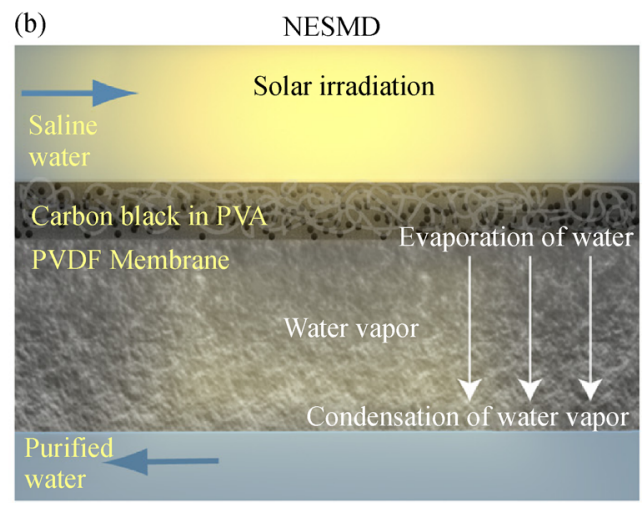

Fig. 7 Photothermal coating which generates localised heat upon direct solar illumination. Reprinted with permission from ref. [123]. Copyright 2017, National Academy of Sciences. 
Future work should also look to compare multiple nanomaterials directly as it is difficult to make accurate comparisons between the work of different research groups due to differences in operating conditions, feed water types, membrane configuration, fabrication conditions etc. Also, the long-term studies on MD are relatively few in number and typically use conventional commercial membranes. It is clear that nanotechnology can improve a host of performance characteristics and so performing long-term pilot studies with more advanced membrane materials is a key area for future research.

Finally, another key attribute of MD compared to other water treatment technologies is its simplicity. The reduced need for pre-treatment steps, such as those required for RO systems, is an advantage which should be explored further and better understood. The design of the membrane is highly consequential in this regard. The ability to produce a low cost, single step, stand-alone system which extracts pure water from a wide variety of feed streams and requires significantly less maintenance (and technical expertise) than current systems would be highly valuable to many communities around the world who currently lack the relevant infrastructure and water availability. Carbon nanomaterials, with their unique set of properties may offer a step towards building and deploying such a system at a time when water scarcity remains a significant global challenge.

Acknowledgements The authors are grateful to the EPSRC for funding under the grant number EP/S032258/1. Sebastian Leaper would like to acknowledge EPSRC for funding this work through the NOWNANO CDT.

Open Access This article is licensed under a Creative Commons Attribution 4.0 International License, which permits use, sharing, adaptation, distribution and reproduction in any medium or format, as long as you give appropriate credit to the original author(s) and the source, provide a link to the Creative Commons licence, and indicate if changes were made. The images or other third party material in this article are included in the article's Creative Commonslicence, unless indicated otherwise in a credit line to the material. If material is not included in the article's Creative Commons licence and your intended use is not permitted by statutory regulation or exceeds the permitted use, you will need to obtain permission directly from the copyright holder. To view a copy of this licence, visit http://creativecommons.org/licenses/by/4.0/.

\section{References}

1. Lawson K W, Lloyd D R. Membrane distillation. Journal of Membrane Science, 1997, 124(1): 1-25

2. Alkhudhiri A, Darwish N, Hilal N. Membrane distillation: a comprehensive review. Desalination, 2012, 287: 2-18

3. Banat F A, Simandl J. Removal of benzene traces from contaminated water by vacuum membrane distillation. Chemical Engineering Science, 1996, 51(8): 1257-1265

4. Nthunya L N, Gutierrez L, Derese S, Nxumalo E N, Verliefde A R, Mamba B B, Mhlanga S D. A review of nanoparticle-enhanced membrane distillation membranes: membrane synthesis and applications in water treatment. Journal of Chemical Technology and Biotechnology (Oxford, Oxfordshire), 2019, 94(9): 27572771

5. Schofield R, Fane A, Fell C. Heat and mass transfer in membrane distillation. Journal of Membrane Science, 1987, 33(3): 299-313

6. Baghbanzadeh M, Rana D, Lan C Q, Matsuura T. Zero thermal input membrane distillation, a zero-waste and sustainable solution for freshwater shortage. Applied Energy, 2017, 187: 910-928

7. Al-Obaidani S, Curcio E, Macedonio F, Di Profio G, Al-Hinai H, Drioli E. Potential of membrane distillation in seawater desalination: thermal efficiency, sensitivity study and cost estimation. Journal of Membrane Science, 2008, 323(1): 85-98

8. Meindersma G, Guijt C, De Haan A. Desalination and water recycling by air gap membrane distillation. Desalination, 2006, 187(1-3): 291-301

9. Khayet M. Solar desalination by membrane distillation: dispersion in energy consumption analysis and water production costs (a review). Desalination, 2013, 308: 89-101

10. Martinetti C R, Childress A E, Cath T Y. High recovery of concentrated RO brines using forward osmosis and membrane distillation. Journal of Membrane Science, 2009, 331(1-2): 31-39

11. Naidu G, Jeong S, Choi Y, Vigneswaran S. Membrane distillation for wastewater reverse osmosis concentrate treatment with water reuse potential. Journal of Membrane Science, 2017, 524: 565-575

12. Lee S, Choi J, Park Y G, Shon H, Ahn C H, Kim S H. Hybrid desalination processes for beneficial use of reverse osmosis brine: current status and future prospects. Desalination, 2018, 454: 104111

13. Yan Z, Yang H, Qu F, Yu H, Liang H, Li G, Ma J. Reverse osmosis brine treatment using direct contact membrane distillation: effects of feed temperature and velocity. Desalination, 2017, 423: 149156

14. Drioli E, Wu Y, Calabro V. Membrane distillataion in the treatment of aqueous solutions. Journal of Membrane Science, 1987, 33(3): 277-284

15. Wu Y, Drioli E. The behaviour of membrane distillation of concentrated aqueous solution. Water Treatment, 1989, 4: 399-415

16. Drioli E, Di Profio G, Curcio E. Progress in membrane crystallization. Current Opinion in Chemical Engineering, 2012, 1(2): $178-182$

17. Quist-Jensen C A, Ali A, Mondal S, Macedonio F, Drioli E. A study of membrane distillation and crystallization for lithium recovery from high-concentrated aqueous solutions. Journal of Membrane Science, 2016, 505: 167-173

18. Quist-Jensen C A, Sørensen J M, Svenstrup A, Scarpa L, Carlsen T S, Jensen H C, Wybrandt L, Christensen M L. Membrane crystallization for phosphorus recovery and ammonia stripping from reject water from sludge dewatering process. Desalination, 2018, 440: 156-160

19. Zarebska A, Nieto D R, Christensen K V, Norddahl B. Ammonia recovery from agricultural wastes by membrane distillation: fouling characterization and mechanism. Water Research, 2014, 56: $1-10$

20. Cui Z, Zhang Y, Li X, Wang X, Drioli E, Wang Z, Zhao S. Optimization of novel composite membranes for water and mineral recovery by vacuum membrane distillation. Desalination, 2018, 440: $39-47$ 
21. Leaper S, Abdel-Karim A, Gad-Allah T A, Gorgojo P. Air-gap membrane distillation as a one-step process for textile wastewater treatment. Chemical Engineering Journal, 2018, 360: 1330-1340

22. Ramlow H, Machado R A F, Marangoni C. Direct contact membrane distillation for textile wastewater treatment: a state of the art review. Water Science and Technology, 2017, 76(10): 25652579

23. Wu Y, Kong Y, Liu J, Zhang J, Xu J. An experimental study on membrane distillation-crystallization for treating waste water in taurine production. Desalination, 1991, 80(2-3): 235-242

24. Quist-Jensen C A, Macedonio F, Drioli E. Membrane technology for water production in agriculture: desalination and wastewater reuse. Desalination, 2015, 364: 17-32

25. Xie M, Shon H K, Gray S R, Elimelech M. Membrane-based processes for wastewater nutrient recovery: technology, challenges, and future direction. Water Research, 2016, 89: 210-221

26. Cath T Y, Adams D, Childress A E. Membrane contactor processes for wastewater reclamation in space. II. Combined direct osmosis, osmotic distillation, and membrane distillation for treatment of metabolic wastewater. Journal of Membrane Science, 2005, 257(12): 111-119

27. Kim H C, Shin J, Won S, Lee J Y, Maeng S K, Song K G. Membrane distillation combined with an anaerobic moving bed biofilm reactor for treating municipal wastewater. Water Research, 2015, 71: 97-106

28. Jiao B, Cassano A, Drioli E. Recent advances on membrane processes for the concentration of fruit juices: a review. Journal of Food Engineering, 2004, 63(3): 303-324

29. Andrés-Mañas J A, Ruiz-Aguirre A, Acién F G, Zaragoza G. Performance increase of membrane distillation pilot scale modules operating in vacuum-enhanced air-gap configuration. Desalination, 2020, 475: 114202

30. Khayet M, Godino P, Mengual J I. Nature of flow on sweeping gas membrane distillation. Journal of Membrane Science, 2000, 170 (2): 243-255

31. El-Bourawi M S, Ding Z, Ma R, Khayet M. A framework for better understanding membrane distillation separation process. Journal of Membrane Science, 2006, 285(1-2): 4-29

32. Gonzalez D, Amigo J, Suarez F. Membrane distillation: perspectives for sustainable and improved desalination. Renewable \& Sustainable Energy Reviews, 2017, 80: 238-259

33. Deka B J, Guo J X, Khanzada N K, An A K. Omniphobic reentrant PVDF membrane with $\mathrm{ZnO}$ nanoparticles composite for desalination of low surface tension oily seawater. Water Research, 2019, 165: 114982

34. Wang W, Du X W, Vahabi H, Zhao S, Yin Y M, Kota A K, Tong T $Z$. Trade-off in membrane distillation with monolithic omniphobic membranes. Nature Communications, 2019, 10(1): 3220

35. Smolders K, Franken A. Terminology for membrane distillation. Desalination, 1989, 72(3): 249-262

36. Drioli E, Ali A, Macedonio F. Membrane distillation: recent developments and perspectives. Desalination, 2015, 356: 56-84

37. Kiss A A, Readi O M K. An industrial perspective on membrane distillation processes. Journal of Chemical Technology and Biotechnology (Oxford, Oxfordshire), 2018, 93(8): 2047-2055

38. Alsebaeai M K, Ahmad A L. Membrane distillation: progress in the improvement of dedicated membranes for enhanced hydrophobicity and desalination performance. Journal of Industrial and Engineering Chemistry, 2020, 86: 13-34

39. Hanemaaijer J H. Memstill®—low cost membrane distillation technology for seawater desalination. Desalination, 2004, 168: 355

40. Zhao K, Heinzl W, Wenzel M, Büttner S, Bollen F, Lange G, Heinzl S, Sarda N. Experimental study of the memsys vacuummulti-effect-membrane-distillation (V-MEMD) module. Desalination, 2013, 323: 150-160

41. Pouyfaucon A B, García-Rodríguez L. Solar thermal-powered desalination: a viable solution for a potential market. Desalination, 2018, 435: 60-69

42. Deshmukh A, Boo C, Karanikola V, Lin S H, Straub A P, Tong T Z, Warsinger D M, Elimelech M. Membrane distillation at the water-energy nexus: limits, opportunities, and challenges. Energy \& Environmental Science, 2018, 11(5): 1177-1196

43. Dai L M, Chang D W, Baek J B, Lu W. Carbon nanomaterials for advanced energy conversion and storage. Small, 2012, 8(8): 11301166

44. Jariwala D, Sangwan V K, Lauhon L J, Marks T J, Hersam M C. Carbon nanomaterials for electronics, optoelectronics, photovoltaics, and sensing. Chemical Society Reviews, 2013, 42(7): 28242860

45. Bardhan N M. 30 years of advances in functionalization of carbon nanomaterials for biomedical applications: a practical review. Journal of Materials Research, 2017, 32(1): 107-127

46. Song Y S, Youn J R. Properties of epoxy nanocomposites filled with carbon nanomaterials. E-Polymers, 2004, 4(1), 80

47. Thines R K, Mubarak N M, Nizamuddin S, Sahu J N, Abdullah E C, Ganesan P. Application potential of carbon nanomaterials in water and wastewater treatment: a review. Journal of the Taiwan Institute of Chemical Engineers, 2017, 72: 116-133

48. Llobet E. Gas sensors using carbon nanomaterials: a review. Sensors and Actuators. B, Chemical, 2013, 179: 32-45

49. Zhao Y, Nakamura R, Kamiya K, Nakanishi S, Hashimoto K. Nitrogen-doped carbon nanomaterials as non-metal electrocatalysts for water oxidation. Nature Communications, 2013, 4(1): 2390

50. Hirsch A. The era of carbon allotropes. Nature Materials, 2010, 9 (11): 868-871

51. Sholl D S, Lively R P. Seven chemical separations to change the world. Nature, 2016, 532(7600): 435-437

52. Falcao E H L, Wudl F. Carbon allotropes: beyond graphite and diamond. Journal of Chemical Technology and Biotechnology (Oxford, Oxfordshire), 2007, 82(6): 524-531

53. Geim A K, Novoselov K S. The rise of graphene. Nature Materials, 2007, 6(3): 183-191

54. Reich S, Li L, Robertson J. Control the chirality of carbon nanotubes by epitaxial growth. Chemical Physics Letters, 2006, 421(4-6): 469-472

55. Kroto H W, Allaf A W, Balm S P. C60-Buckminsterfullerene. Chemical Reviews, 1991, 91(6): 1213-1235

56. Svensson M, Zhang F L, Veenstra S C, Verhees W J H, Hummelen J C, Kroon J M, Inganas O, Andersson M R. High-performance polymer solar cells of an alternating polyfluorene copolymer and a fullerene derivative. Advanced Materials, 2003, 15(12): 988-991 
57. Coro J, Suarez M, Silva L S R, Eguiluz K I B, Salazar-Banda G R. Fullerene applications in fuel cells: a review. International Journal of Hydrogen Energy, 2016, 41(40): 17944-17959

58. Amorphous-carbon R J. Advances in Physics, 1986, 35(4): $317-$ 374

59. Punetha V D, Rana S, Yoo H J, Chaurasia A, McLeskey J T, Ramasamy M S, Sahoo N G, Cho J W. Functionalization of carbon nanomaterials for advanced polymer nanocomposites: a comparison study between CNT and graphene. Progress in Polymer Science, 2017, 67: 1-47

60. Nair R R, Wu H A, Jayaram P N, Grigorieva I V, Geim A K. Unimpeded permeation of water through helium-leak-tight graphene-based membranes. Science, 2012, 335(6067): 442-444

61. Boukhvalov D W, Katsnelson M I, Son Y W. Origin of anomalous water permeation through graphene oxide membrane. Nano Letters, 2013, 13(8): 3930-3935

62. Yang T, Lin H, Loh K P, Jia B. Fundamental transport mechanisms and advancements of graphene oxide membranes for molecular separation. Chemistry of Materials, 2019, 31(6): 1829-1846

63. $\mathrm{Hu} \mathrm{M}$, Mi B. Enabling graphene oxide nanosheets as water separation membranes. Environmental Science \& Technology, 2013, 47(8): 3715-3723

64. Vasu K, Prestat E, Abraham J, Dix J, Kashtiban R, Beheshtian J, Sloan J, Carbone P, Neek-Amal M, Haigh S. Van der Waals pressure and its effect on trapped interlayer molecules. Nature Communications, 2016, 7: 12168

65. Wei $\mathrm{N}$, Peng $\mathrm{X}, \mathrm{Xu} \mathrm{Z}$. Understanding water permeation in graphene oxide membranes. ACS Applied Materials \& Interfaces, 2014, 6(8): 5877-5883

66. Thomas J A, McGaughey A J. Reassessing fast water transport through carbon nanotubes. Nano Letters, 2008, 8(9): 2788-2793

67. Majumder M, Chopra N, Andrews R, Hinds B J. Nanoscale hydrodynamics: enhanced flow in carbon nanotubes. Nature, 2005, 438(7064): 44

68. Secchi E, Marbach S, Niguès A, Stein D, Siria A, Bocquet L. Massive radius-dependent flow slippage in carbon nanotubes. Nature, 2016, 537(7619): 210

69. Zhang H, Liu B, Kieu H T, Wu M S, Zhou K, Law A W K. Coarsegrained molecular dynamics study of membrane distillation through meso-size graphene channels. Journal of Membrane Science, 2018, 558: 34-44

70. Celebi K, Buchheim J, Wyss R M, Droudian A, Gasser P, Shorubalko I, Kye J I, Lee C, Park H G. Ultimate permeation across atomically thin porous graphene. Science, 2014, 344(6181): 289-292

71. Strathmann H, Kock K. The formation mechanism of phase inversion membranes. Desalination, 1977, 21(3): 241-255

72. Menut P, Su Y, Chinpa W, Pochat-Bohatier C, Deratani A, Wang D, Huguet P, Kuo C, Lai J, Dupuy C. A top surface liquid layer during membrane formation using vapor-induced phase separation (VIPS) - evidence and mechanism of formation. Journal of Membrane Science, 2008, 310(1-2): 278-288

73. Park H C, Kim Y P, Kim H Y, Kang Y S. Membrane formation by water vapor induced phase inversion. Journal of Membrane Science, 1999, 156(2): 169-178

74. Smolders C, Reuvers A, Boom R, Wienk I. Microstructures in phase-inversion membranes. Part 1. Formation of macrovoids. Journal of Membrane Science, 1992, 73(2-3): 259-275

75. Woo Y C, Kim Y, Shim W G, Tijing L D, Yao M, Nghiem L D, Choi J S, Kim S H, Shon H K. Graphene/PVDF flat-sheet membrane for the treatment of RO brine from coal seam gas produced water by air gap membrane distillation. Journal of Membrane Science, 2016, 513: 74-84

76. Athanasekou C, Sapalidis A, Katris I, Savopoulou E, Beltsios K, Tsoufis T, Kaltzoglou A, Falaras P, Bounos G, Antoniou M, et al. Mixed matrix PVDF/graphene and composite-skin PVDF/graphene oxide membranes applied in membrane distillation. Polymer Engineering and Science, 2019, 59: E262-E278

77. Leaper S, Abdel-Karim A, Faki B, Luque-Alled J M, Alberto M, Vijayaraghavan A, Holmes S M, Szekely G, Badawy M I, Shokri N. Flux-enhanced PVDF mixed matrix membranes incorporating APTS-functionalized graphene oxide for membrane distillation. Journal of Membrane Science, 2018, 554: 309-323

78. Abdel-Karim A, Luque-Alled J M, Leaper S, Alberto M, Fan X, Vijayaraghavan A, Gad-Allah T A, El-Kalliny A S, Szekely G, Ahmed S I. PVDF membranes containing reduced graphene oxide: effect of degree of reduction on membrane distillation performance. Desalination, 2019, 452: 196-207

79. Ganesh B M, Isloor A M, Ismail A F. Enhanced hydrophilicity and salt rejection study of graphene oxide-polysulfone mixed matrix membrane. Desalination, 2013, 313: 199-207

80. Xu Z W, Zhang J G, Shan M J, Li Y L, Li B D, Niu J R, Zhou B M, Qian X M. Organosilane-functionalized graphene oxide for enhanced antifouling and mechanical properties of polyvinylidene fluoride ultrafiltration membranes. Journal of Membrane Science, 2014, 458: 1-13

81. Ragunath S, Roy S, Mitra S. Carbon nanotube immobilized membrane with controlled nanotube incorporation via phase inversion polymerization for membrane distillation based desalination. Separation and Purification Technology, 2018, 194: 249-255

82. Fahmey M S, El-Aassar A H M, Abo-Elfadel M M, Orabi A S, Das R. Comparative performance evaluations of nanomaterials mixed polysulfone: a scale-up approach through vacuum enhanced direct contact membrane distillation for water desalination. Desalination, 2019, 451: 111-116

83. Bhadra M, Roy S, Mitra S. Nanodiamond immobilized membranes for enhanced desalination via membrane distillation. Desalination, 2014, 341: 115-119

84. Bhadra M, Roy S, Mitra S. Flux enhancement in direct contact membrane distillation by implementing carbon nanotube immobilized PTFE membrane. Separation and Purification Technology, 2016, 161: 136-143

85. Bhadra M, Roy S, Mitra S. Desalination across a graphene oxide membrane via direct contact membrane distillation. Desalination, 2016, 378: 37-43

86. Intrchom W, Roy S, Humoud M, Mitra S. Immobilization of graphene oxide on the permeate side of a membrane distillation membrane to enhance flux. Membranes, 2018, 8(3): 63

87. Dumee L F, Sears K, Schutz J, Finn N, Huynh C, Hawkins S, Duke M, Gray S. Characterization and evaluation of carbon nanotube bucky-paper membranes for direct contact membrane distillation. Journal of Membrane Science, 2010, 351(1-2): 36-43 
88. Seo D H, Pineda S, Woo Y C, Xie M, Murdock A T, Ang E Y M, Jiao Y, Park M J, Lim S I, Lawn M, et al. Anti-fouling graphenebased membranes for effective water desalination. Nature Communications, 2018, 9(1): 683

89. Xu Z, Yan X, Du Z, Li J, Cheng F. Effect of oxygenic groups on desalination performance improvement of graphene oxide-based membrane in membrane distillation. Separation and Purification Technology, 2020, 251: 117304

90. Han M Y, Dong T, Hou D Y, Yao J M, Han L. Carbon nanotube based Janus composite membrane of oil fouling resistance for direct contact membrane distillation. Journal of Membrane Science, 2020, 607: 118078

91. Intrchom W, Roy S, Mitra S. Functionalized carbon nanotube immobilized membrane for low temperature ammonia removal via membrane distillation. Separation and Purification Technology, 2020, 235: 116188

92. Grasso G, Galiano F, Yoo M J, Mancuso R, Park H B, Gabriele B, Figoli A, Drioli E. Development of graphene-PVDF composite membranes for membrane distillation. Journal of Membrane Science, 2020, 604: 118017

93. Mao Y, Huang Q, Meng B, Zhou K, Liu G, Gugliuzza A, Drioli E, Jin W. Roughness-enhanced hydrophobic graphene oxide membrane for water desalination via membrane distillation. Journal of Membrane Science, 2020, 611: 118364

94. Formhals A. Process and apparatus for preparing artificial threads. US patent, 1975 504, 1934-10-02

95. Formhals A. Artificial thread and method of producing same. US patent, 2187 306, 1940-01-16

96. Formhals A. Production of artificial fibers from fiber forming liquids. US patent, 2323 025, 1943-06-29

97. Formhals A. Method and apparatus for spinning. US patent, 2349 950, 1944-05-30

98. Persano L, Camposeo A, Tekmen C, Pisignano D. Industrial upscaling of electrospinning and applications of polymer nanofibers: a review. Macromolecular Materials and Engineering, 2013, 298(5): 504-520

99. Li D, Xia Y. Electrospinning of nanofibers: reinventing the wheel? Advanced Materials, 2004, 16(14): 1151-1170

100. Ahmed F E, Lalia B S, Hashaikeh R. A review on electrospinning for membrane fabrication: challenges and applications. Desalination, 2015, 356: 15-30

101. Tijing L D, Choi J S, Lee S, Kim S H, Shon H K. Recent progress of membrane distillation using electrospun nanofibrous membrane. Journal of Membrane Science, 2014, 453: 435-462

102. Woo Y C, Tijing L D, Shim W G, Choi J S, Kim S H, He T, Drioli E, Shon H K. Water desalination using graphene-enhanced electrospun nanofiber membrane via air gap membrane distillation. Journal of Membrane Science, 2016, 520: 99-110

103. Tijing L D, Woo Y C, Shim W G, He T, Choi J S, Kim S H, Shon H K. Superhydrophobic nanofiber membrane containing carbon nanotubes for high-performance direct contact membrane distillation. Journal of Membrane Science, 2016, 502: 158-170

104. Lee J G, Lee E J, Jeong S, Guo J X, An A K, Guo H, Kim J, Leiknes T, Ghaffour N. Theoretical modeling and experimental validation of transport and separation properties of carbon nanotube electrospun membrane distillation. Journal of Membrane
Science, 2017, 526: 395-408

105. Sun M, Boo C, Shi W B, Rolf J, Shaulsky E, Cheng W, Plata D L, $\mathrm{Qu}$ J H, Elimelech M. Engineering carbon nanotube forest superstructure for robust thermal desalination membranes. Advanced Functional Materials, 2019, 29(36): 1903125

106. Bhaskar P, Bosworth L A, Wong R, O’Brien M A, Kriel H, Smit E, McGrouther D A, Wong J K, Cartmell S H. Cell response to sterilized electrospun poly(-caprolactone) scaffolds to aid tendon regeneration in vivo. Journal of Biomedical Materials Research. Part A, 2017, 105(2): 389-397

107. Li K L, Zhang Y, Xu L L, Zeng F F, Hou D Y, Wang J. Optimizing stretching conditions in fabrication of PTFE hollow fiber membrane for performance improvement in membrane distillation. Journal of Membrane Science, 2018, 550: 126-135

108. Intrchom W, Roy S, Mitra S. Removal and recovery of methyl tertiary butyl ether (MTBE) from water using carbon nanotube and graphene oxide immobilized membranes. Nanomaterials (Basel, Switzerland), 2020, 10(3): 578

109. Mansour S, Giwa A, Hasan S W. Novel graphene nanoplateletscoated polyethylene membrane for the treatment of reject brine by pilot-scale direct contact membrane distillation: an optimization study. Desalination, 2018, 441: 9-20

110. Lee C L, Chen C H, Chen C W. Graphene nanosheets as ink particles for inkjet printing on flexible board. Chemical Engineering Journal, 2013, 230: 296-302

111. Lotya M, Hernandez Y, King P J, Smith R J, Nicolosi V, Karlsson L S, Blighe F M, De S, Wang Z M, McGovern I T, et al. Liquid phase production of graphene by exfoliation of graphite in surfactant/water solutions. Journal of the American Chemical Society, 2009, 131(10): 3611-3620

112. Huang Y, Li H, Wang L, Qiao Y L, Tang C B, Jung C I, Yoon Y M, Li S G, Yu M. Ultrafiltration membranes with structure-optimized graphene-oxide coatings for antifouling oil/water separation. Advanced Materials Interfaces, 2015, 2(2): 1400433

113. Choi W, Choi J, Bang J, Lee J H. Layer-by-layer assembly of graphene oxide nanosheets on polyamide membranes for durable reverse-osmosis applications. ACS Applied Materials \& Interfaces, 2013, 5(23): 12510-12519

114. Hegab H M, Zou L D. Graphene oxide-assisted membranes: fabrication and potential applications in desalination and water purification. Journal of Membrane Science, 2015, 484: 95-106

115. Koenig S P, Wang L D, Pellegrino J, Bunch J S. Selective molecular sieving through porous graphene. Nature Nanotechnology, 2012, 7(11): 728-732

116. Morin A, Lucot D, Ouerghi A, Patriarche G, Bourhis E, Madouri A, Ulysse C, Pelta J, Auvray L, Jede R, et al. FIB carving of nanopores into suspended graphene films. Microelectronic Engineering, 2012, 97: 311-316

117. Nthunya L N, Gutierrez L, Lapeire L, Verbeken K, Zaouri N, Nxumalo E N, Mamba B B, Verliefde A R, Mhlanga S D. Foulingresistant PVDF nanofibre membranes for the desalination of brackish water in membrane distillation. Separation and Purification Technology, 2019, 228: 115793

118. Ahmed F E, Hilal N, Hashaikeh R. Electrically conductive membranes for in situ fouling detection in membrane distillation using impedance spectroscopy. Journal of Membrane Science, 
2018, 556: 66-72

119. Dudchenko A V, Chen C, Cardenas A, Rolf J, Jassby D. Frequency-dependent stability of CNT joule heaters in ionizable media and desalination processes. Nature Nanotechnology, 2017, 12(6): 557-563

120. Duan W Y, Ronen A, Walker S, Jassby D. Polyaniline-coated carbon nanotube ultrafiltration membranes: enhanced anodic stability for in situ cleaning and electro-oxidation processes. ACS Applied Materials \& Interfaces, 2016, 8(34): 22574-22584

121. Liu H, Vajpayee A, Vecitis C D. Bismuth-doped tin oxide-coated carbon nanotube network: improved anode stability and efficiency for flow-through organic electrooxidation. ACS Applied Materials \& Interfaces, 2013, 5(20): 10054-10066

122. Janas D, Kreft S K, Boncel S, Koziol K K K. Durability and surface chemistry of horizontally aligned CNT films as electrodes upon electrolysis of acidic aqueous solution. Journal of Materials Science, 2014, 49(20): 7231-7243
123. Dongare P D, Alabastri A, Pedersen S, Zodrow K R, Hogan N J, Neumann O, Wu J J, Wang T X, Deshmukh A, Elimelech M, et al. Nanophotonics-enabled solar membrane distillation for off-grid water purification. Proceedings of the National Academy of Sciences of the United States of America, 2017, 114(27): 69366941

124. Jiang R B, Cheng S, Shao L, Ruan Q F, Wang J F. Mass-based photothermal comparison among gold nanocrystals, $\mathrm{PbS}$ nanocrystals, organic dyes, and carbon black. Journal of Physical Chemistry C, 2013, 117(17): 8909-8915

125. Yang K, Zhang S A, Zhang G X, Sun X M, Lee S T, Liu Z A. Graphene in mice: ultrahigh in vivo tumor uptake and efficient photothermal therapy. Nano Letters, 2010, 10(9): 3318-3323

126. Robinson J T, Tabakman S M, Liang Y Y, Wang H L, Casalongue H S, Vinh D, Dai H J. Ultrasmall reduced graphene oxide with high near-infrared absorbance for photothermal therapy. Journal of the American Chemical Society, 2011, 133(17): 6825-6831 